\title{
補間点拡大法の $\mathcal{L}_{1}, \mathcal{H}_{\infty}$ 制御問題での収束性に関する考察
}

\author{
太田 快 人*·後藤修* \\ A Study on the Convergence of the Interpolation Point Augmentation Method for \\ $\mathcal{L}_{1}$ and $\mathcal{H}_{\infty}$ Control Problems \\ Yoshito Онта* and Osamu Goто**

\begin{abstract}
This paper studies the convergence of the interpolation augmentation method applied to multi-block $\mathcal{H}_{\infty}$ and $\mathcal{L}_{1}$ control problems. Firstly, it is shown that the norm of the Hankel operator of the augmented 1 block problems converges to the norm of the Hankel Toeplitz operator of the multi block problem for $\mathcal{H}_{\infty}$ problems. Secondly, it is shown that the norm of the upper bound sequence approaches the optimum under some conditions for $\mathcal{L}_{1}$ 2-block problems to guarantee the suboptimality of the sequence.
\end{abstract}

Key Words: $\mathcal{H}_{\infty}$ control, Hankel-Toeplitz operator, $\mathcal{L}_{1}$ control, weak-* topology

\section{1.はじめに}

閉ループ系の作用素ノルムを規範とした制御系設計手法は, ロバスト制御の中心的な考え方になっている. 制御系内の信 号の大きさをその最大振幅とするとき, 作用素ノルムはイン パルス応答の $\mathcal{L}_{1}\left(\ell_{1}\right)$ ノルムで与えられるので, ここから $\mathcal{L}_{1}$ $\left(\ell_{1}\right)$ 制御問題が提唱されている ${ }^{1)}$.

この問題に対する解は, 1 ブロック問題とよばれるクラス については離散時間系は文献 2) で，連続時間系は文献 3) で それぞれ一般解が得られている。しかし, 制御のトレードオ フを扱う多くの問題のクラスである多ブロック問題について は，その解法への取り組みは遅れていた。

文献 4) では, 多ブロック離散時間 $\ell_{1}$ 制御問題の求解法と して遅れ拡大法を提案している.ブロック拡大をして 1 ブ ロック問題を構成して, その最適解よりもとの多ブロック問 題への上界列と下界列を構成して解こうとするものである. その理論背景としては, 離散時間 $\ell_{1}$ 制御問題を考えるとき に用いるノルム空間の性質を陽に用いているために，連続時 間系への適用は不可能である.

補間点拡大法 ${ }^{5)}$ は, 個々の空間の性質ではなく沉弱位相の 性質を用いることにより, 遅れ拡大法を拡張して, 多ブロッ

†第 39 回システム制御情報学会研究発表講演会で一部発表 $(1995 \cdot 5)$, 第 25 回制御理論シンポジウムで一部発表 (1996. 5)

* 大阪大学工学部 吹田市山田丘 2-1

** 住友金属工業 (株) 総合技術研究所 大阪市此花区島屋 5-1-109

* Faculty of Engineering, Osaka University, Suita

** Corporate Research and Development Laboratories, Sumitomo Metal Industries, Ltd., Konohana-ku, Osaka (Received September 9, 1996)
ク連続時間 $\mathcal{L}_{1}$ 制御問題の解法を与えている．収束性は，沉 弱閉部分空間のもつ性質から得られているため, 拡大ブロッ クは不安定零点をもつように構成すればよく, 遅れ拡大法の ように離散時間の遅れに限定されることはない。また沉弱位 相の性質から $\mathcal{H}_{\infty}$ 制御問題に適用しても最適解が得られる.

補間点拡大法を適用するためには，その収束性に関して明 確にしておかなければならないことがいくつかある。一つに は，拡大ブロックを構成することの意味が不明確であり，既 存理論との関係が十分解明されていない，次に，沉弱収束は， ノルムでの収束よりも弱いために, 拡大を途中で打ち切った ときの準最適性（最適值に任意の誤差で近い解が得られるこ と）が保証されていない.

本論文では，これらの点に対して考察を加える．具体的に は次のような結果を得ている，まず，補間点拡大法の収束性 を多ブロック問題に対するハンケルテプリッツ作用素と拡大 1 ブロック問題に対するハンケル作用素の相互関係を明確に することにより，よりわかりやすいものとする．ハンケル作 用素はハンケルテプリッツ作用素の一部分（正確にはコンプ レッションとよばれる）にあたり，補間点の拡大につれて， より大きな空間でのコンプレッションに相当するため, ハン ケル作用素のノルム值の最適値への収束が言える。これは, $\mathcal{H}_{\infty}$ 制御での議論である.

次に, $\mathcal{L}_{1}$ 制御の場合, 列 2 ブロック問題について, 上界 列のノルム值が最適值に収束することは, 従来, 下界列のデ ル夕関数のサポートが一様に間隔があいているという条件で 得られていた ${ }^{5)}$ 。この一様な間隔の仮定よりも緩い仮定のも とでもノルム值の収束が結論できることが示される。この結 果，上界列の準最適性が保証される。 
Table 1 Classes of input-output operators

\begin{tabular}{c|c|c}
\hline \hline 制御問題 & 信号空間 & 安定入出力作用素のクラス \\
\hline 離散時間 $\mathcal{H}_{\infty}$ 問題 & $\ell_{2}\left(Z_{+}\right)$ & 伝達関数 $\mathcal{H}_{\infty}(D)$ \\
連続時間 $\mathcal{H}_{\infty}$ 問題 & $\mathcal{L}_{2}\left(R_{+}\right)$ & 伝達関数 $\mathcal{H}_{\infty}\left(C_{+}\right)$ \\
離散時間 $\ell_{1}$ 問題 & $\ell_{\infty}\left(Z_{+}\right)$ & たたみ込積 $\ell_{1}\left(R_{+}\right)$ \\
連続時間 $\mathcal{L}_{1}$ 問題 & $\mathcal{L}_{\infty}\left(R_{+}\right)$ & たたみ込積 $M\left(R_{+}\right)$ \\
\hline \hline
\end{tabular}

\section{2. 補間点拡大法}

いわゆる標準問題は安定化補償器のパラメータ化を用いる と，次のようなモデルマッチング問題に記述できる.

$$
\gamma=\inf \left\{\|\Phi\|_{\text {ind }}: \Phi=H-U Q V, Q \in \mathcal{A}\right\}
$$

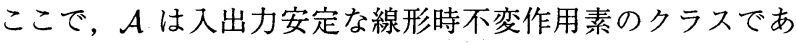
り，制御問題に応じて Table 1 のように定める。 また $H$, $U, V \in \mathcal{A}$ は一般化プラントより決定される固定された作用 素である。なお， $Z_{+}$は非負整数の集合， $R_{+}$は非負実数の 集合, $D$ は複素平面の開単位円内, $C_{+}$は複素平面の開右半 面である。

一入力一出力系の場合， $\mathcal{A}$ の具体的な作用は，次のよう になっている（文献 5) を参照）。信号空間の元である入力 ならびに出力をそれぞれ $u, y$ として離散時間ならば $\lambda$ 変 換 (不安定領域を単位円内にするために $z$ 変換で $\lambda=z^{-1}$ とおいた変換），連続時間ならばラプラス変換を $\hat{u}, \hat{y} て ゙$ 表 わす。離散時間（連続時間） $\mathcal{H}_{\infty}$ 問題では， $\hat{H} \in \mathcal{H}_{\infty}(D)$ $\left(\hat{H} \in \mathcal{H}_{\infty}\left(C_{+}\right)\right)$の作用は $\hat{y}=\hat{H} \hat{u}$ である.ここで記号の 若干の乱用をして，これらの作用に基づく作用素を $H \in \mathcal{A}$ とも書く. 離散時間 $\ell_{1}$ 問題では， $H \in \ell_{1}$ の作用は，畳み込 み積

$$
y(t)=\sum_{\tau=0}^{t} u(t-\tau) H(\tau)
$$

である。その伝達関数は，

$$
\hat{H}(\lambda)=\sum_{\tau=0}^{\infty} \lambda^{\tau} H(\tau)
$$

である，伝達関数は， $\mathcal{H}_{\infty}(D)$ に属することが知られている. 連続時間 $\mathcal{L}_{1}$ 問題では, $H \in M\left(R_{+}\right)$の作用は, 畳み込み積

$$
y(t)=\int_{\tau \in[0, t]} u(t-\tau) d H(\tau)
$$

である。その伝達関数は,

$$
\hat{H}(s)=\int_{\tau \in R_{+}} e^{-s \tau} d H(\tau)
$$

である．伝達関数は， $\mathcal{H}_{\infty}\left(C_{+}\right)$に属することが知られてい る. 多入力多出力系の場合, $\mathcal{A}$ の要素をもつ行列として入出 力作用素が決められている.

式 (1) で, 伝達関数 $\hat{H}, \hat{U}, \hat{V}$ は有理関数であると仮定す る. $U, V$ のサイズがともに正方となる問題を 1 ブロック問 題, $U$ の出力数が入力数をうわまわるか $V$ 入力数が出力数 をうわまわるとき多ブロック問題という． 1 ブロック問題で
かつ伝達関数 $\hat{U}, \hat{V}$ が安定領域と不安定領域の境界（連続 時間系ならば虚軸，離散時間系ならば単位円）の上に零点を 持たないときには，問題 (1) は最適解をもつ. 多ブロック問 題のときには， $U, V$ のサイズにあわせて $H, U, V$ を分割 して

$$
\begin{aligned}
& H=\left[\begin{array}{ll}
H_{11} & H_{12} \\
H_{21} & H_{22}
\end{array}\right], U=\left[\begin{array}{l}
U_{1} \\
U_{2}
\end{array}\right], \\
& V=\left[\begin{array}{ll}
V_{1} & V_{2}
\end{array}\right]
\end{aligned}
$$

とする.

[仮定 1］ブロック分割 2は以下を満たす.

(i). $U_{1}, V_{1}$ は正方で， $\hat{U}_{1}$ および $\hat{V}_{1}$ は行列式が恒等的には 0 ではない.

(ii). $U_{1}, V_{1}$ の不安定零点は境界上（連続時間系では虚軸, 離散時間系では単位円上）にない。

（注意） ここで, 条件 (i) は $\hat{U}$ および $\hat{V}$ がそれぞれ列最 大階数または行最大階数であれば，行または列の入れ換えに よって満たすことができる，条件 (ii) は, 議論の簡単化のた めに必要である。

ここで, $U, V$ をブロック拡大して

$$
\begin{aligned}
& U_{a}^{(k)}=\left[\begin{array}{cc}
U & X_{c}^{(k)}
\end{array}\right]=\left[\begin{array}{cc}
U_{1} & 0 \\
U_{2} & X_{2, c}^{(k)}
\end{array}\right] \\
& V_{a}^{(k)}=\left[\begin{array}{c}
V \\
X_{r}^{(k)}
\end{array}\right]=\left[\begin{array}{cc}
V_{1} & V_{2} \\
0 & X_{2, r}^{(k)}
\end{array}\right]
\end{aligned}
$$

とおき, 1 ブロック問題

$$
\begin{aligned}
\gamma_{a}^{(k)} & =\inf \left\{\|\Phi\|: \Phi=H-U_{a}^{(k)} Q_{a} V_{a}^{(k)}, Q_{a} \in \mathcal{A}\right\} \\
Q_{a} & =\left[\begin{array}{ll}
Q_{11} & Q_{12} \\
Q_{21} & Q_{22}
\end{array}\right]
\end{aligned}
$$

を考える。

[仮定 2] $X_{2, c}^{(k)}$ と $X_{2, r}^{(k)}$ は以下を満たす.

(i). 安定有理式である.

(ii). 無限遠点を含む虚軸 (離散時間系の場合は単位円周) 上 に零点をもたない。

(iii). 安定有理式環において $\hat{X}_{2, c}^{(k)}$ は $\hat{X}_{2, c}^{(k+1)}$ の左因子, $\hat{X}_{2, r}^{(k)}$ は $\hat{X}_{2, r}^{(k+1)}$ の右因子である.

(iv). すべての単因子の零点は, $k \rightarrow \infty$ のきに右半面 (離 散時間系の場合は単位円内) に集積点をもつ.

（注意） $\quad \hat{X}_{2, c}^{(k)}$ および $\hat{X}_{2, r}^{(k)}$ を文献 5)のように単位行列の スカラー伝達関数倍とすれば，これらの条件を満たす構成は 具体的に与えることができる，条件 (iv) は，最小の単因子の 零点が問題となるので, ブロッキング零点が不安定領域に集 積点をもつことと等価である.

このとき拡大された 1 ブロック問題 (5) は最適解をもつの で，それを

$$
\Phi^{(k)}=H-U_{a}^{(k)} Q^{(k)} V_{a}^{(k)},
$$




$$
Q^{(k)}=\left[\begin{array}{ll}
Q_{11}^{(k)} & Q_{12}^{(k)} \\
Q_{21}^{(k)} & Q_{22}^{(k)}
\end{array}\right]
$$

とおき，余分なフリーパラメータを除いて

$$
\Psi^{(k)}=H-U Q^{(k)} V
$$

とする.このとき

$$
\left\|\Phi^{(k)}\right\|=\gamma_{a}^{(k)} \leq \gamma \leq\left\|\Psi^{(k)}\right\|
$$

が成り立つ.また下界列 $\left\{\Phi^{(k)}\right\}$ と上界列 $\left\{\Psi^{(k)}\right\}$ は次のよ うな意味で多ブロックモデルマッチング問題 (1) の最適解に 近付く.

《定理 1》拡大 1 ブロック問題 (5) が仮定 2 を満たすときそ の最適解 (6) の列 は汎弱収束する部分列 $\left\{\Phi^{\left(k_{i}\right)}\right\}$ をつ.こ のとき

$$
\text { weak- } * \lim \Phi^{\left(k_{i}\right)}=\text { weak- } * \lim \Psi^{\left(k_{i}\right)}=\Phi^{(o)}
$$

であり, $\Phi^{(o)}$ は多ブロック問題 $(1)$ の最適解である.

（証明）式 (6) と式 (7)より,

$$
\Phi^{(k)}=\Psi^{(k)}-\left(R_{1}^{(k)}+R_{2}^{(k)}+R_{3}^{(k)}\right)
$$

ただし

$$
\begin{aligned}
& R_{1}^{(k)}=X_{c}^{(k)} Q_{21}^{(k)} V \\
& R_{2}^{(k)}=U Q_{12}^{(k)} X_{r}^{(k)} \\
& R_{3}^{(k)}=X_{c}^{(k)} Q_{22}^{(k)} X_{r}^{(k)}
\end{aligned}
$$

という関係がある。これらを成分ごとに書いて，

$$
\begin{aligned}
\Phi_{11}^{(k)}= & \Psi_{11}^{(k)} \\
\Phi_{12}^{(k)}= & \Psi_{12}^{(k)}-U_{1} Q_{12}^{(k)} X_{2, r}^{(k)} \\
\Phi_{21}^{(k)}= & \Psi_{21}^{(k)}-X_{2, c}^{(k)} Q_{21}^{(k)} V_{1} \\
\Phi_{22}^{(k)}= & \Psi_{22}^{(k)}-\left(U_{2} Q_{12}^{(k)} X_{2, r}^{(k)}\right. \\
& \left.\quad+X_{2, c}^{(k)} Q_{21}^{(k)} V_{2}+X_{2, c}^{(k)} Q_{22}^{(k)} X_{2, r}^{(k)}\right)
\end{aligned}
$$

を得る.ここで文献 5) の補題 5 を用いると, $\left\{\Phi_{11}^{(k)}\right\}$ の有 界性から $\left\{Q_{11}^{(k)}\right\}$ が有界であることが導かれ，結局 $\left\{\Psi^{(k)}\right\}$ も有界となる。すると, $\left\{U_{1} Q_{12}^{(k)} X_{2, r}^{(k)}\right\}$ む $\left\{X_{2, c}^{(k)} Q_{21}^{(k)} V_{1}\right\}$ が有界である。ここで再び文献 5) の補題 5 を用いて $\left\{Q_{12}^{(k)} X_{2, r}^{(k)}\right\}$ と $\left\{X_{2, c}^{(k)} Q_{21}^{(k)}\right\}$ が有界であることがわかる. 寸 ると $\left\{X_{2, c}^{(k)} Q_{22}^{(k)} X_{2, r}^{(k)}\right\}$ もまた有界である. ここで, 文献 5) の補題 4 を多入力多出力系に拡大した命題を利用すれば汎弱 位相で $Q_{12}^{(k)} X_{2, r}^{(k)} \rightarrow 0, X_{2, c}^{(k)} Q_{21}^{(k)} \rightarrow 0, X_{2, c}^{(k)} Q_{22}^{(k)} X_{2, r}^{(k)} \rightarrow 0$ を結論することができる。

\section{3. 補間点拡大とハンケルテプリッツ作用素}

$\mathcal{H}_{\infty}$ の 1 ブロック問題の最適值はハンケル作用素のノル ムに等しく, 多ブロック制御問題の最適值は混合ハンケルテ プリッツ作用素のノルムに等しいことが知られている ${ }^{6)}$ 。こ こでは, 補間点拡大法を $\mathcal{H}_{\infty}$ 制御問題に適用したときに得ら れる 1 ブロック問題に対応したハンケル作用素と, もとの多
ブロック問題に対応したハンケルテプリッツ作用素の関係を 明確にする．具体的には，ハンケル作用素のノルム值がハン ケルテプリッツ作用素のノルム值に収束することが示される。 これは, 補間点拡大法での下界値の最適値への収束の別証明 になる。なお，この節は連続時間系, 離散時間系の双方に適 用できるが説明を簡単にするために連続時間系のみを扱う。

\section{1 ハンケルテプリッツ作用素}

時間領域での信号空間 $\mathcal{L}_{2}(R)$ はフーリエ変換により周波 数領域での信号空間 $\mathcal{L}_{2}$ に同形である.つまり $f \in \mathcal{L}_{2}(R)$

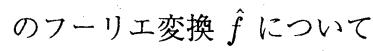

$$
\begin{aligned}
\|f\|^{2} & =\int_{-\infty}^{\infty} f(t)^{*} f(t) d t \\
& =\frac{1}{2 \pi} \int_{-\infty}^{\infty} \hat{f}(j \omega)^{*} \hat{f}(j \omega) d \omega=\|\hat{f}\|^{2}
\end{aligned}
$$

が成り立つ.ここで, 時間軸 $R$ を正の時刻 $R_{+}$と負の時刻 $R_{-}$に分割すればそれに応じて周波数領域も

$$
\mathcal{L}_{2}=\mathcal{H}_{2}\left(C_{+}\right) \oplus \mathcal{H}_{2}\left(C_{-}\right)
$$

と分割される.ここで $C_{-}$は複素平面の開左半面である. $\mathcal{L}_{2}$ から $\mathcal{H}_{2}\left(C_{ \pm}\right)$への直交射影を $\Pi_{ \pm}$で表す.

虚軸上で有界な行列の空間 $\mathcal{L}_{\infty}$ において $\mathcal{L}_{2}$ の要素と の掛け算 $\hat{M}(j \omega) \hat{f}(j \omega)$ は $\mathcal{L}_{2}$ 上の作用素となる。これを $M: \mathcal{L}_{2} \rightarrow \mathcal{L}_{2}$ で表すものとする. $\mathcal{H}_{\infty}\left(C_{+}\right)$はその虚軸への 極限をとることにより $\mathcal{L}_{\infty}$ の部分空間であるがその対応す る作用素は $\mathcal{H}_{2}\left(C_{+}\right)$を不変にする.

$\mathcal{H}_{\infty}$ モデルマッチング問題 (1) を考える.ここで, インナー アウター分解をしたのちアウター部分を自由パラメータ $Q$ に 含めることにより $\hat{U}$ ははじめからインナーであるとしてょい. 同様に $\hat{V}$ はコインナーであるとする. 安定有理伝達関数 $\hat{M} に$ 対してそのパラコンジュゲイト $\hat{M}^{\sim}$ を $\hat{M}^{\sim}(s)=\hat{M}(-s)^{\top}$ と定める.

1 ブロック問題であるときにはハンケル作用素

$$
\left.\Pi_{-} U^{\sim} H V^{\sim}\right|_{\mathcal{H}_{2}\left(C_{+}\right)}
$$

のノルムはモデルマッチング問題 (1) と同じ值をとる. 多ブ ロック問題のときには,

$$
\left[\begin{array}{ll}
\hat{U} & \hat{U}_{c}
\end{array}\right],\left[\begin{array}{c}
\hat{V} \\
\hat{V}_{r}
\end{array}\right]
$$

が正方のインナーになるように $\hat{U}_{c}, \hat{V}_{r}$ を決める ${ }^{7)}$ 。このと きハンケルテプリッツ作用素

$$
\Gamma_{H T}=\left[\begin{array}{cc}
\left.\Pi_{-} U^{\sim} H V^{\sim}\right|_{\mathcal{H}_{2}\left(C_{+}\right)} & \Pi_{-} U^{\sim} H V_{r}^{\sim} \\
\left.U_{c}^{\sim} H V^{\sim}\right|_{\mathcal{H}_{2}\left(C_{+}\right)} & U_{c}^{\sim} H V_{r}^{\sim}
\end{array}\right] \text { (9) }
$$

のノルムはモデルマッチング問題 $(1)$ と同じ値をとる ${ }^{6)}$.

\section{2 補間点拡大法との関係}

式 (3), (4) の拡大ブロックは, 仮定 2 に加えて次を満たす ものとする。

[仮定 3] 拡大された $U_{a}^{(k)}\left(V_{a}^{(k)}\right)$ は以下を満たす. (i). $\hat{U}^{\sim} \hat{X}_{c}^{(k)}\left(\hat{X}_{r}^{(k)} \hat{V}^{\sim}\right)$ は安定有理式である. 
(ii). $\hat{U}_{c}^{\sim} \hat{X}_{c}^{(k)}\left(\hat{X}_{r}^{(k)} \hat{V}_{r}^{\sim}\right)$ は安定有理式であり, その行列式 は恒等的に 0 ではなく，加無限遠を含む虚軸上に零点を もたない.

（注意） 仮定 3 を満たす $\hat{X}_{c}^{(k)}$ と $\hat{X}_{r}^{(k)}$ を構成することは可 能である。積が安定有理式になるためには $\hat{U}^{\sim}$ などの不安 定極を相殺する零点を持たせればよい．また(ii)の条件は， $\left[\begin{array}{ll}\hat{U} & \hat{U}_{c}\end{array}\right]$ の $(1,1)$ ブロック $\hat{U}_{1}$ が境界上に零点をもたな いので, $\left[\begin{array}{ll}\hat{U} & \hat{U}_{c}\end{array}\right]^{\sim}$ の $(2,2)$ ブロックは境界上で正則と なることから満たされる。

このとき, 拡大 1 ブロック問題 (5) に対応したハンケル作 用素は次のようにして計算される. まず (3) 式のインナーア ウター分解を計算する。

$$
\left[\begin{array}{c}
\hat{U}^{\sim} \\
\hat{U}_{c}^{\sim}
\end{array}\right] \hat{U}_{a}^{(k)}=\left[\begin{array}{cc}
I & \hat{U}^{\sim} \hat{X}_{c}^{(k)} \\
0 & \hat{U}_{c}^{\sim} \hat{X}_{c}^{(k)}
\end{array}\right]
$$

であるから, $\hat{U}_{c}^{\sim} \hat{X}_{c}^{(k)}=\hat{Y}_{c, i}^{(k)} \hat{Y}_{c, o}^{(k)}$ とインナーアウター分解 して

$$
\hat{U}_{a}^{(k)}=\left[\begin{array}{cc}
\hat{U} & \hat{U}_{c} \hat{Y}_{c, i}^{(k)}
\end{array}\right]\left[\begin{array}{cc}
I & \hat{U}^{\sim} \hat{X}_{c}^{(k)} \\
0 & \hat{Y}_{c, o}^{(k)}
\end{array}\right]
$$

を得る. (4) 式についても同様にコインナーアウター分解 $\hat{X}_{r}^{(k)} \hat{V}_{r}^{\sim}=\hat{Y}_{r, c o}^{(k)} \hat{Y}_{r, c i}^{(k)}$ をして

$$
\hat{V}_{a}^{(k)}=\left[\begin{array}{cc}
I & 0 \\
\hat{X}_{r}^{(k)} \hat{V}^{\sim} & \hat{Y}_{r, c o}^{(k)}
\end{array}\right]\left[\begin{array}{c}
\hat{V} \\
\hat{Y}_{r, c i}^{(k)} \hat{V}_{r}
\end{array}\right]
$$

である。これより拡大 1 ブロック問題 (5) に対応したハンケ ル作用素は

$$
\begin{aligned}
\Gamma_{H}^{(k)}= & {\left[\begin{array}{c}
\left.\Pi_{-} U^{\sim} H V^{\sim}\right|_{\mathcal{H}_{2}\left(C_{+}\right)} \\
\left.\Pi_{-} Y_{c, i}^{(k) \sim} U_{c}^{\sim} H V^{\sim}\right|_{\mathcal{H}_{2}\left(C_{+}\right)} \\
\left.\Pi_{-} U^{\sim} H V_{r}^{\sim} Y_{r, c i}^{(k) \sim}\right|_{\mathcal{H}_{2}\left(C_{+}\right)} \\
\left.\Pi_{-} Y_{c, i}^{(k) \sim} U_{c}^{\sim} H V_{r}^{\sim} Y_{r, c i}^{(k) \sim}\right|_{\mathcal{H}_{2}\left(C_{+}\right)}
\end{array}\right] }
\end{aligned}
$$

となることがわかる.

《定理 2》仮定 2,3 のもとで, 拡大 1 ブロック問題に対応 したハンケル作用素 (10) と多ブロック問題に対応したハンケ ルテプリッッ作用素 $(9)$ は

$$
\lim _{k \rightarrow \infty}\left\|\Gamma_{H}^{(k)}\right\|=\left\|\Gamma_{H T}\right\|
$$

\section{を満たす。}

（証明） ハンケル作用素 (10) とハンケルテプリッツ作用 素(9)を比べると,

$$
\Gamma_{H}^{(k)}=\left[\begin{array}{cc}
I & 0 \\
0 & \Pi_{-} Y_{c, i}^{(k) \sim}
\end{array}\right] \Gamma_{H T}\left[\begin{array}{cc}
I & 0 \\
0 & \left.Y_{r, c i}^{(k) \sim}\right|_{\mathcal{H}_{2}\left(C_{+}\right)}
\end{array}\right]
$$

という関係がある。そこで,

$$
\Lambda^{(k)}=\left[\begin{array}{cc}
I & 0 \\
0 & \left.Y_{c, i}^{(k)}\right|_{\mathcal{H}_{2}\left(C_{-}\right)}
\end{array}\right] \Gamma_{H}^{(k)}\left[\begin{array}{cc}
I & 0 \\
0 & \Pi_{+} Y_{r, c i}^{(k)}
\end{array}\right]
$$

とおくと $\Lambda^{(k)} \rightarrow \Gamma_{H T} \quad(\mathrm{SOT})\left(\right.$ 作用素の強い位相 ${ }^{8)}$ での収 束）であることがわかる．実際

$$
\begin{aligned}
& \Pi_{c}^{(k)}=\left[\begin{array}{ccc}
I & 0 \\
0 & \left.Y_{c, i}^{(k)}\right|_{\mathcal{H}_{2}\left(C_{-}\right)} \Pi_{-} Y_{c, i}^{(k) \sim}
\end{array}\right] \\
& \Pi_{r}^{(k)}=\left[\begin{array}{ccc}
I & 0 \\
0 & \left.Y_{r, c i}^{(k) \sim}\right|_{\mathcal{H}_{2}\left(C_{+}\right)} \Pi_{+} Y_{r, c i}^{(k)}
\end{array}\right]
\end{aligned}
$$

とすれば, $\Pi_{i}^{(k) *}=\Pi_{i}^{(k)}, \Pi_{i}^{(k) 2}=\Pi_{i}^{(k)}, i=r$ または $c$ であ るので, これらは射影作用素である.ここで $\Pi_{i}^{(k)} \rightarrow I$ (SOT) である.なぜなら $\cdots \supset Y_{c, i}^{(k)} \mathcal{H}_{2}\left(C_{+}\right) \supset Y_{c, i}^{(k+1)} \mathcal{H}_{2}\left(C_{+}\right) \supset$ $\cdots, \cap_{k} Y_{c, i}^{(k)} \mathcal{H}_{2}\left(C_{+}\right)=(0)$ であるので, その $\mathcal{L}_{2}$ での直交 補空間を考えると, $\cdots \subset Y_{c, i}^{(k)} \mathcal{H}_{2}\left(C_{-}\right) \subset Y_{c, i}^{(k+1)} \mathcal{H}_{2}\left(C_{-}\right) \subset$ $\cdots, \oplus_{k} Y_{c, i}^{(k)} \mathcal{H}_{2}\left(C_{-}\right)=\mathcal{L}_{2}$ となる.そこで $f \in \mathcal{L}_{2}$ と $\epsilon>0$ を与えると, 自然数 $k>0$ と $g \in \mathcal{H}_{2}\left(C_{-}\right)$を選 んで $\left\|f-Y_{c, i}^{(k)} g\right\|<\epsilon$ とできる.すると

$$
\begin{aligned}
& \quad\left|f-Y_{c, i}^{(k)}\right|_{\mathcal{H}_{2}\left(C_{-}\right)} \Pi_{-} Y_{c, i}^{(k) \sim} f \| \\
= & \| f-\left.Y_{c, i}^{(k)}\right|_{\mathcal{H}_{2}\left(C_{-}\right)} \Pi_{-} Y_{c, i}^{(k) \sim}\left(f-Y_{c, i}^{(k)} g\right) \\
& \quad-\left.Y_{c, i}^{(k)}\right|_{\mathcal{H}_{2}\left(C_{-}\right)} \Pi_{-} Y_{c, i}^{(k) \sim} Y_{c, i}^{(k)} g \| \\
\leq & \left(1+\left\|\left.Y_{c, i}^{(k)}\right|_{\mathcal{H}_{2}\left(C_{-}\right)} \Pi_{-} Y_{c, i}^{(k) \sim}\right\|\right)\left\|f-Y_{c, i}^{(k)} g\right\| \\
\leq & 2 \epsilon
\end{aligned}
$$

である. $\Pi_{r}^{(k)} \rightarrow I \quad(\mathrm{SOT}) も$ 同様に示される。する と $\Lambda^{(k)}=\Pi_{c}^{(k)} \Gamma_{H T} \Pi_{r}^{(k)} \rightarrow \Gamma_{H T}(\mathrm{SOT})$ である ${ }^{8)}$.こ こから $\liminf \left\|\Lambda^{(k)}\right\| \geq\left\|\Gamma_{H T}\right\|$ を得る。一方 $\left\|\Lambda^{(k)}\right\|=$ $\left\|\Pi_{c}^{(k)} \Gamma_{H T} \Pi_{r}^{(k)}\right\| \leq\left\|\Gamma_{H T}\right\|$ より $\lim \left\|\Lambda^{(k)}\right\|=\left\|\Gamma_{H T}\right\|$ で ある. 最後に $\left\|\Lambda^{(k)}\right\|=\left\|\Gamma_{H}^{(k)}\right\|$ であるから定理が証明され た.

（注意）・ヒルベルト空間 $X$ の作用素の列 $\left\{T_{k}\right\}$ が作用素 の強い位相で $T$ に収束するという意味は, 任意の $x \in X$ について $\left\|T_{k} x-T x\right\| \rightarrow 0$ が成り立つことである（文献 8) 参照).

(注意). ハンケル作用素 $\Gamma_{H}^{(k)}$ と対応する作用素 $\Lambda^{(k)}=$ $\Pi_{c}^{(k)} \Gamma_{H T} \Pi_{r}^{(k)}$ はハンケルテプリッッ作用素 $\Gamma_{H T}$ のコンプ レッションである，射影作用素 $\Pi_{c}^{(k)}$ および $\Pi_{r}^{(k)}$ が作用素 の強い位相で恒等写像に収束することから,この意味で補間 点拡大法によるハンケル作用素がもとの多ブロック問題の八 ンケルテプリッツ作用素に近付いていることがわかる.

\section{4. $\mathcal{L}_{1}$ 制御への適用}

補間点拡大法では上界列は沉弱位相による収束が保証され る. 点列 $\left\{\Phi^{(k)}\right\}$ が $\Phi^{(o)}$ に沉弱収束するとき

$$
\left\|\Phi^{(o)}\right\| \leq \liminf _{k}\left\|\Phi^{(k)}\right\|
$$

という関係しか得られないので,一般には補間点数を有限回 
で打ち切ったときに任意の精度で準最適性を保証することが できない.

文献 ${ }^{5)}$ では，ある制約をもった列 2 ブロック問題の中の クラスでは, 1 ブロック問題の最適解のデル夕関数の間隔が 一様にあいているという仮定のもとで，準最適性が示された (文献 5) ではある制約を設定していないが，この結果は誤り である．正しくは，定理 3 と同じく $\hat{U}_{2} \hat{U}_{1}^{-1}$ の直達項に関する 制約のもとに成立する). 本論文では, デル夕関数の間隔の 一様性よりも緩い仮定のもとで，同じ結論が得られることを 示す.

\section{列 2 ブロック問題は}

$$
\begin{aligned}
& \gamma=\inf \{\|\Phi\|: \\
& \left.\Phi=\left[\begin{array}{l}
H_{1} \\
H_{2}
\end{array}\right]-\left[\begin{array}{l}
U_{1} \\
U_{2}
\end{array}\right] Q, Q \in M\left(R_{+}\right)\right\}
\end{aligned}
$$

であり，その拡大 1 ブロック問題は

$$
\begin{gathered}
\gamma_{a}^{(k)}=\inf \{\|\Phi\|: \\
\Phi=\left[\begin{array}{c}
H_{1} \\
H_{2}
\end{array}\right]-\left[\begin{array}{cc}
U_{1} & 0 \\
U_{2} & X_{2, c}^{(k)}
\end{array}\right]\left[\begin{array}{c}
Q_{1} \\
Q_{2}
\end{array}\right], \\
\left.Q_{1}, Q_{2} \in M\left(R_{+}\right)\right\}
\end{gathered}
$$

である，下界列抢よび上界列は

$$
\Phi^{(k)}=\left[\begin{array}{c}
\Phi_{1}^{(k)} \\
\Phi_{2}^{(k)}
\end{array}\right]=\left[\begin{array}{c}
H_{1}-U_{1} Q_{1}^{(k)} \\
H_{2}-U_{2} Q_{1}^{(k)}-X_{2, c}^{(k)} Q_{2}^{(k)}
\end{array}\right]
$$

ならびに

$$
\Psi^{(k)}=\left[\begin{array}{c}
\Psi_{1}^{(k)} \\
\Psi_{2}^{(k)}
\end{array}\right]=\left[\begin{array}{c}
H_{1}-U_{1} Q_{1}^{(k)} \\
H_{2}-U_{2} Q_{1}^{(k)}
\end{array}\right]
$$

と構成される.ここで $\Psi_{1}^{(k)}=\Phi_{1}^{(k)}$ と $\Psi_{2}^{(k)}=\Phi_{2}^{(k)}+h^{(k)} Q^{(2)}$ であることに注意する. $\Phi_{1, i}^{(o)}$ で $\Phi_{1}^{(o)}$ の $i$ 番目の行を表す. また行列の各行が高々 1 つの非零要素からなるとき行選択行 列とよぶ.

《定理 3》 列 2 ブロック問題 (11) において $\hat{H}(s)$ は真に プロパーであり, $\hat{U}_{2} \hat{U}_{1}^{-1}$ の直達項は行選択行列である とする。もし $\Phi^{(o)} \in M\left(R_{+}\right)$が絶対連続部分をもたず， $\left\|\Phi_{1}^{(o)}\right\|=\left\|\Phi^{(o)}\right\|=\gamma$ であるならば

$$
\lim _{k}\left\|\Psi^{(k)}\right\|=\gamma
$$

が成り立つ.

（証明）まず,

$$
\begin{aligned}
\hat{\Psi}_{2}^{(k)} & =\hat{H}_{2}-\hat{U}_{2} \hat{U}_{1}^{-1} \hat{H}_{1}+\hat{U}_{2} \hat{U}_{1}^{-1} \hat{\Phi}_{1}^{(k)} \hat{\Psi}_{2}^{(o)} \\
& =\hat{H}_{2}-\hat{U}_{2} \hat{U}_{1}^{-1} \hat{H}_{1}+\hat{U}_{2} \hat{U}_{1}^{-1} \hat{\Phi}_{1}^{(o)}
\end{aligned}
$$

である.ここで, $\hat{U}_{1}^{-1}$ は有理関数であるので, 両側逆ラプラ ス変換が定義されている．すると

$$
\begin{aligned}
\Psi_{2}^{(k)}=W_{1}+W_{20} \Phi^{(k)}+W_{2 M} * \Phi_{1}^{(k)} \\
\Psi_{2}^{(o)}=W_{1}+W_{20} \Phi^{(k)}+W_{2 M} * \Phi_{1}^{(o)} \\
\text { が } \mathcal{L}_{1}\left(R_{-}\right) \times M\left(R_{+}\right) \text {で成り立つ. ただし } W_{1} \in L_{1}(R) \text { は }
\end{aligned}
$$

$\hat{H}_{2}-\hat{U}_{2} \hat{U}_{1}^{-1} \hat{H}_{1}$ の逆ラプラス変換であり, $W_{20} \in R$ は $\hat{U}_{2} \hat{U}_{1}^{-1}$ の直達項であり, $W_{2 M} \in L_{1}(R)$ は $\hat{U}_{2} \hat{U}_{1}^{-1}$ の真にプロパー な部分の逆ラプラス変換である. $W_{2 M} \in \mathcal{L}_{1}(R) \cap C_{0}(R)$ に 注意する．付録の補題 1 より $W_{2 M} * \Phi^{(k)} \rightarrow W_{2 M} * \Phi^{(o)}$ が 成り立つ。すると

$$
\left\|\Psi_{2}^{(k)}\right\| \rightarrow\left\|\Psi_{2}^{(o)}\right\|=\left\|\Phi_{2}^{(o)}\right\| \leq \gamma .
$$

である。

(注意) 外成信号数が $n_{w}=1$ である（したがって $n_{u}=n_{y}=1$ である) ときには, $\hat{U}_{2} \hat{U}_{1}^{-1}$ の直達項は行 選択行列である。

（注意） 文献 5) で仮定されたデル夕関数の間隔の一様性 は，極限がやはりデル夕関数の和になるための十分条件であ るので,ここで示された結果は，拡張になっている.

\section{5. おわりに}

補間点拡大法について，その収束性に関して下界列と上界 列に対して考察を加えた．まず，下界列に関しては，多ブロッ ク問題はハンケルテプリッッ作用素に対応するが, 拡大 1 ブ ロック問題に対応したハンケル作用素はそのノルム值がハン ケルテプリッツ作用素のノルム值に近付くことがわかった， これは補間点拡大法と従来の理論の関係を説明するものであ る. 上界列に関しては $\mathcal{L}_{1}$ 制御問題での上界列の沉弱位相よ りも強い収束性については十分な結果が得られていなかった が，ある仮定のもとにノルム值の最適值への収束が示された。

\section{参 考 文 献}

1) M. Vidyasagar: Optimal rejection of persistent bounded disturbances, IEEE Trans. Automatic Control, AC-31-6, $527 / 534(1986)$

2) M.A. Dahleh and J.B. Pearson: $\ell_{1}$-optimal feedback controllers for MIMO discrete-time systems, IEEE Trans. Automatic Control, AC-32-4, 314/322 (1987)

3) M.A. Dahleh and J.B. Pearson: $L_{1}$-optimal compensators for continuous-time systems, IEEE Trans. Automatic Control, AC-32-10, 889/895 (1987)

4) I.J. Diaz-Bobillo and M.A. Dahleh: Minimization of the maximum peak-to-peak gain: the general multiblock problem, IEEE Trans. Automatic Control, AC-38-10, 1459/1482 (1993)

5) Y. Ohta, N. Adachi and H. Kimura: Interpolation point augmentation method for multiblock model matching problems: multi-input multi-output $L_{1}$ optimal control, Proc. of 33rd IEEE Conf. Decision and Control, 3137/3142 (1994)

6) B.A. Nagy and C. Foiaş: Harmonic Analysis of Operators on Hilbert Space, North-Holland (1970)

7) K. Glover: All optimal Hankel-norm approximation of linear multivariable systems and their $L^{\infty}$-error bounds, Int. J. Control, 39-6, 1115/1193 (1984)

8) J.B. Conway: A Course in Functional Analysis, SpringerVarlag (1985)

9) E. Hille and R.S. Phillips: Functional Analysis and SemiGroups, American Mathematical Society Colloquium Publication, XXXI (1957) 
《付

\section{録》}

\section{A. 連続時間 $\mathcal{L}_{1}$ 制御に関連した空間の数学的性質}

$M\left(R_{+}\right)$は，たたみ込み積をもつバナッ八環である時問軸 を負の方向に拡張して, 空間 $\mathcal{L}_{1}(R), C_{0}(R)$ を考える。 ま ず, $G \in C_{0}(R), \Phi \in M\left(R_{+}\right)$に対して

$$
\langle G, \Phi\rangle=\int_{\tau \in R_{+}} G(\tau) d \Phi(\tau)
$$

によって $M\left(R_{+}\right)$は，自然に $C_{0}(R)$ の双対空間の部分空間 となる。次に畳み込み積を $G \in \mathcal{L}_{1}(R), \Phi \in M\left(R_{+}\right)$に対 して, $F=G * \Phi \in \mathcal{L}_{1}(R)$ を

$$
F(t)=\int_{\tau \in R_{+}} G(t-\tau) d \Phi(\tau)
$$

と定義することが可能である．ここで $F \in \mathcal{L}_{1}$ であることは， 文献 9) の結果を若干拡張すれば導かれる.

$X \subset R$ をボレル集合とする. 特性関数 $\chi$ は

$$
\chi(t)= \begin{cases}1, & (t \in X) \\ 0, & (t \notin X)\end{cases}
$$

で定められる。ここで若干の記号の乱用をして $\Phi \in M\left(R_{+}\right)$ について $\chi \Phi \in M\left(R_{+}\right)$を

$$
\int_{\tau \in T} d \chi \Phi=\int_{\tau \in T \cap X} d \Phi
$$

と定める. また $G \in \mathcal{L}_{1}(R)$ について $\chi G \in \mathcal{L}_{1}(R)$ を $(\chi G)(t)=\chi(t) G(t)$ と定める. 以下, これらの空間のいく つかの性質をまとめておく.

[性質 1] $\Phi \in M\left(R_{+}\right)$とする. $\epsilon>0$ とするとき $t_{1}>0$ を 十分大きく選ぶと $\|\chi \Phi\|<\epsilon$ である. ただし $\chi$ は区間 $\left[t_{1}, \infty\right)$ の特性関数である.

（証明） $\Phi$ は有界変動であることから導かれる。

[性質 2] $\left\{\Phi^{(k)}\right\} \subset M\left(R_{+}\right)$を有界な沉弱収束列とし, $\Phi^{(o)}=$ weak- $* \lim \Phi^{(k)}$ とする. $\lim \left\|\Phi^{(k)}\right\|=\left\|\Phi^{(o)}\right\|$ が成 り立つと仮定する。このとき $\epsilon>0$ に対して $t_{1}>0$ を適当に 選ぶと十分大きな $k$ について $\left\|\chi \Phi^{(o)}\right\|<\epsilon$ と $\left\|\chi^{(k)}\right\|<\epsilon$ が成り立つ.ただし $\chi$ は区間 $\left\{t: t \geq t_{1}\right\}$ の特性関数である. （証明） 特異測度は, ルベーグ測度 0 の集合上にサポー 卜をもつので, $\Phi^{(k)}, k=1,2, \cdots と \Phi^{(o)}$ の特異部分のサ ポート集合の和集合も測度 0 である。そこで区間 $\left[t_{0}, t_{1}\right]$ $\left(0<t_{0}<t_{1}\right)$ を $t_{0}, t_{1}$ がサポート集合の和集合上になく $\chi_{0}$ を区間 $\left[t_{0}, \infty\right)$ の特性関数とするとき $\left\|\chi_{0} \Phi^{(o)}\right\|<\epsilon / 3$ が成り立つように選ぶ (性質 1参照).すると $\|F\|=1$, $F(t)=0, t>t_{1}$ であり $\left\langle F, \Phi^{(o)}\right\rangle>\left\|\Phi^{(o)}\right\|-\epsilon / 2$ を満た す $F \in C_{0}\left(R_{+}\right)$がある.このとき十分大きな $k$ について $\left\|\chi \Phi^{(k)}\right\|<\epsilon$ が成り立たないとすれば整数列 $k_{i}, k_{i} \rightarrow \infty$ を $\left\langle F, \Phi^{\left(k_{i}\right)}\right\rangle<\left\|\Phi^{\left(k_{i}\right)}\right\|-\epsilon$ と選ぶことができるが, そうであ れば $\left\langle F, \Phi^{(o)}\right\rangle=\lim \left\langle F, \Phi^{\left(k_{i}\right)}\right\rangle \leq\left\|\Phi^{(o)}\right\|-\epsilon$ であることに なり矛盾を生じる。

[性質 3] $\Phi \in M\left(R_{+}\right), G \in \mathcal{L}_{1}(R) \cap C_{0}(R)$ とすれば $G * \Phi$ は連続関数である。
（証明） $G \in C_{0}(R)$ より $G$ は一様連続である。任意 の $\epsilon>0$ に対して $\delta>0$ があって $|h|<\delta$ ならば $|G(t+h)-G(t)|<\epsilon$ とできるので

$$
\begin{aligned}
& |F(t+h)-F(t)| \\
= & \left|\int_{\tau \in R_{+}}(G(t+h-\tau)-G(t-\tau)) d \Phi(\tau)\right| \\
\leq & \int_{\tau \in R_{+}}|G(t+h-\tau)-G(t-\tau)| d|\Phi|(\tau) \\
< & \epsilon\|\Phi\|
\end{aligned}
$$

である。

[性質 4] $\Phi \in M\left(R_{+}\right), G \in \mathcal{L}_{1}(R) \cap C_{0}(R)$ とする. $\epsilon>0$ を任意に与えるとき $t_{0}<0$ があって， $\chi_{0}$ を区間 $\left(-\infty, t_{0}\right)$ の特性関数とすれば,

(1) $\sup \left|\chi_{0}(G * \Phi)(t)\right|<\epsilon$

(2) $\left\|\chi_{0}(G * \Phi)\right\|_{1}<\epsilon$

が成り立つ。

（証明）（一様ノルムについて） $t_{0}$ を十分小さくとれ ば, $G \in C_{0}(R)$ より $\sup \left|\chi_{0} G(t)\right|<\epsilon /\|\Phi\|$ である.すると $t<t_{0}$ であれば

$$
\begin{aligned}
|(G * \Phi)(t)| & =\left|\int_{\tau \in R_{+}} G(t-\tau) d \Phi(\tau)\right| \\
& \leq \int_{\tau \in R_{+}}|G(t-\tau)| d|\Phi|(\tau)<\epsilon
\end{aligned}
$$

である.( 1 ノルムについて $) t_{0}$ を十分小さくとれば， $G \in \mathcal{L}_{1}(R)$ より $\left\|\chi_{0} G\right\|_{1}<\epsilon /\|\Phi\|$ である.すると

$$
\begin{aligned}
\left\|\chi_{0}(G * \Phi)\right\|_{1} & =\int_{-\infty}^{t_{0}}\left|\int_{\tau \in R_{+}} G(t-\tau) d \Phi(\tau)\right| d t \\
& \leq \int_{-\infty}^{t_{0}} \int_{\tau \in R_{+}}|G(t-\tau)| d|\Phi|(\tau) d t \\
& =\int_{\tau \in R_{+}} \int_{-\infty}^{t_{0}-\tau}|G(t)| d t d|\Phi|(\tau)<\epsilon
\end{aligned}
$$

である。

[性質 5] 有界な列 $\Phi^{(k)} \in M\left(R_{+}\right), k=1,2, \cdots$ は $\epsilon>0$ を任意にあたえるとき， $t_{1}>0$ があって， $\chi_{1}$ を区間 $\left[t_{1}, \infty\right)$ の特性関数として $\left\|\chi_{1} \Phi^{(k)}\right\|<\epsilon /\left(2 \max _{t}|G(t)|\right)$ を满たす ものとする. $G \in \mathcal{L}_{1}(R) \cap C_{0}(R)$ とする. このとき $t_{2}>t_{1}$ を十分大きくとれば $\chi_{2}$ を区間 $\left[t_{2}, \infty\right)$ の特性関数として

(1) $\sup \left|\chi_{2}\left(G * \Phi^{(k)}\right)(t)\right|<\epsilon$

(2) $\left\|\chi_{2}\left(G * \Phi^{(k)}\right)\right\|_{1}<\epsilon$ が成り立つ。

(証明) (一様ノルムについて) $G \in C_{0}(R)$ より $t_{2}>$ $t_{1}>0$ を $t>t_{2}-t_{1}$ ならば $|G(t)|<\epsilon /\left(2 \sup _{k}\left\|\Phi^{(k)}\right\|\right)$ を 満たすようにする。 $\chi_{0}$ を区間 $\left[0, t_{1}\right)$ の特性関数とする。す ると $t>t_{2}$ ならば

$$
\left|\left(G * \Phi^{(k)}\right)(t)\right|
$$


798

$$
\begin{aligned}
& =\left|\int_{\tau \in R_{+}} G(t-\tau) \Phi^{(k)}(\tau)\right| \\
& \leq \int_{\tau \in R_{+}}|G(t-\tau)| d\left|\chi_{0} \Phi^{(k)}\right|(\tau) \\
& \quad+\int_{\tau \in R_{+}}|G(t-\tau)| d\left|\chi_{1} \Phi^{(k)}\right|(\tau) \\
& \quad \leq \epsilon / 2+\epsilon / 2=\epsilon
\end{aligned}
$$

が成り立つ. (1ノルムについて) $t_{2}>t_{1} を\left\|\chi_{2} G\right\|_{1}<$

$$
\begin{aligned}
&\left\|\chi_{2}\left(G * \Phi^{(k)}\right)\right\|_{1} \\
&= \int_{t_{2}}^{\infty}\left|\int_{\tau \in R_{+}} G(t-\tau) d \Phi^{(k)}(\tau)\right| d t \\
& \leq \int_{t_{2}}^{\infty} \int_{\tau \in R_{+}}|G(t-\tau)| d\left|\Phi^{(k)}\right|(\tau) d t \\
&= \int_{\tau \in R_{+}} \int_{t_{2}-\tau}^{\infty}|G(t)| d t d\left|\chi_{0} \Phi^{(k)}\right|(\tau) \\
& \quad \int_{\tau \in R_{+}} \int_{t_{2}-\tau}^{\infty}|G(t)| d t d\left|\chi_{1} \Phi^{(k)}\right|(\tau) \\
&<\epsilon / 2+\epsilon / 2=\epsilon
\end{aligned}
$$

である。

（注意） 性質 4 およ゙ 5 より，性質 $3 て ゙ ~ F \in C_{0}(R)$ である ことまで結論できる。

以上の性質を用いると定理 3 を証明するために重要となる 次の補題を示すことができる。

[補題 1] $\left\{\Phi^{(k)}\right\} \subset M\left(R_{+}\right)$を有界な沉弱収束列とし, $\Phi^{(o)}=$ weak- * $\lim \Phi^{(k)}$ とする. $\lim \left\|\Phi^{(k)}\right\|=\left\|\Phi^{(o)}\right\|$ が成 り立つと仮定する. $G \in \mathcal{L}_{1}(R) \cap C_{0}(R)$ とする.このとき $G * \Phi^{(k)} \rightarrow G * \Phi^{(o)} \quad\left(\mathcal{L}_{1}(R)\right.$ でのノルム収束) が成り立つ. (証明) $\quad G_{t}(\bullet)=G(t-\bullet)$ とおけば, $G \in C_{0}(R)$ たから $G_{t} \in C_{0}\left(R_{+}\right)$である. 時刻 $t$ での $G * \Phi^{(k)}$ と $G * \Phi^{(o)}$ の評価は, それぞれ線形汎関数 $\left\langle G_{t}, \Phi^{(k)}\right\rangle$ と $\left\langle G_{t}, \Phi^{(o)}\right\rangle$ であ ることに注意すれば各 $t$ で $\left(G * \Phi^{(k)}\right)(t) \rightarrow\left(G * \Phi^{(o)}\right)(t)$ であることがわかる、コンパクトな区間 $\left[t_{a}, t_{b}\right]$ を任意に とる。この区間上への $G * \Phi^{(k)}$ と $G * \Phi^{(o)}$ の制限をそれ ぞれ $f^{(k)}$ と $f^{(o)}$ で表わす. 性質 3 よりこれらは連続関数で あることに注意しておく、このとき $f^{(k)}$ は $f^{(o)}$ に一様収 束する。このことを示すために $t_{a} \leq t_{0} \leq t_{b}$ と $\epsilon>0$ を 固定する. 正数 $\delta^{(o)}\left(t_{0}\right)>0$ を $\left|t-t_{0}\right|<\delta^{(o)}\left(t_{0}\right)$ ならば $\left|f^{(o)}(t)-f^{(o)}\left(t_{0}\right)\right|<\epsilon$ であるように選ぶ.ここで

$$
\begin{aligned}
\delta^{(k)}=\min & \left\{\operatorname { s u p } \left\{\delta:\left|t-t_{0}\right|<\delta\right.\right. \text { ならば } \\
& \left.\left.\left|f^{(k)}(t)-f^{(k)}\left(t_{0}\right)\right|<\epsilon\right\}, \delta^{(o)}\left(t_{0}\right)\right\}
\end{aligned}
$$

と定める。まず， $\delta^{(k)} \rightarrow \delta^{(o)}\left(t_{0}\right)$ である。もしそうでな いとすれば, 必要ならば部分列をとって $t^{(k)},\left|t^{(k)}-t_{0}\right|<$ $\delta^{\prime}<\delta^{(o)}\left(t_{0}\right)$ を $\left|f^{(k)}\left(t^{(k)}\right)-f^{(k)}\left(t_{0}\right)\right| \geq \epsilon$ を満たすよ うに正数 $\delta^{\prime}$ と部分列を選ぶことができる. 列 $\left\{t^{(k)}\right\}$ はコンパクト集合 $\left\{t:\left|t-t_{0}\right| \leq \delta^{\prime}\right\}$ の中に集積点 $t_{c}$ を もつ.すると $\left|f^{(o)}\left(t_{c}\right)-f^{(o)}\left(t_{0}\right)\right| \geq \epsilon$ となるが,これ
は $\delta^{(o)}\left(t_{0}\right)$ の定義に矛盾する。区間 $\left[t_{a}, t_{b}\right]$ を開集合 $\left\{t:\left|t-t_{0}\right|<\delta^{(0)}\left(t_{0}\right) / 2\right\}, t_{a} \leq t_{0} \leq t_{b}$ で覆う. 有限 被覆を選びだし $\left\{t_{0,1}, t_{0,2}, \cdots, t_{0, N}\right\}$ をその添字集合と する. 整数 $k\left(t_{0}\right)>0$ を $k>\left(t_{0}\right)$ ならば $\delta^{(k)}>$ $\delta^{(o)}\left(t_{0}\right) / 2$ かつ $\left|f^{(k)}\left(t_{0}\right)-f^{(o)}\left(t_{0}\right)\right|<\epsilon$ であるように選 ぶ. そして $\delta=\min \left\{\delta^{(o)}\left(t_{0, i}\right): 1 \leq i \leq N\right\}$ とし $k_{0}=$ $\max \left\{k\left(t_{0, i}\right): 1 \leq i \leq N\right\}$ とする，すると $t_{a} \leq t \leq t_{b}$ であ れば, $k>k_{0}$ の場合, ある $t_{0, i}$ について

$$
\begin{aligned}
& \left|f^{(k)}(t)-f^{(o)}(t)\right| \\
\leq & \left|f^{(k)}(t)-f^{(k)}\left(t_{0, i}\right)\right|+\left|f^{(k)}\left(t_{0, i}\right)-f^{(o)}\left(t_{0, i}\right)\right| \\
& \quad+\left|f^{(o)}\left(t_{0, i}\right)-f^{(o)}(t)\right| \\
< & 3 \epsilon
\end{aligned}
$$

が成り立つ.これは一様収束性を示している. ここで $t_{0}<t_{2}$ として区間 $\left(-\infty, t_{0}\right),\left[t_{0}, t_{2}\right),\left[t_{2}, \infty\right)$ の特性関数をそれぞ れ $\chi_{0}, \chi_{1}, \chi_{2}$ とする.

$$
\begin{aligned}
& \left\|G * \Phi^{(k)}-G * \Phi^{(o)}\right\|_{1} \\
& \leq\left\|\chi_{1} G * \Phi^{(k)}-\chi_{1} G * \Phi^{(0)}\right\|_{1} \\
& \quad+\left\|\chi_{0} G * \Phi^{(k)}\right\|_{1}+\left\|\chi_{0} G * \Phi^{(k)}\right\|_{1} \\
& \quad+\left\|\chi_{2} G * \Phi^{(o)}\right\|_{1}+\left\|\chi_{2} G * \Phi^{(o)}\right\|_{1}
\end{aligned}
$$

である。右辺第 2 項と第 3 項は，性質 4 より $t_{0}$ を十分小さ くとればいくらでも小さくできる（kに関して一様に選べる ことに注意). 右辺第 4 項と第 5 項は, 性質 5 より $t_{2}$ を十 分大きくとれば $k$ に関して一様にいくらでも小さくできる （性質 2 を用いた）。証明の前半で示したように，このように 選んだ区間 $\left[t_{0}, t_{2}\right]$ 上での一様収束性より $k$ を十分大きくと れば第 1 項をいくらでも小さくできる.

（注意） 証明は，すべて一入力一出力系について与えたが, 成分ごとに適用することにより多入力多出力系でも補題 1 は 成立する。

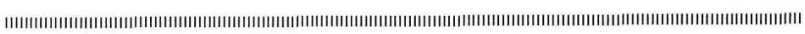

$$
\text { [著 者 紹 介] }
$$

太田快人（正会員）

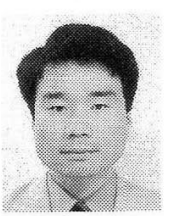

1980 年大阪大学工学部電子工学科卒業. 1983 年大阪大学大学院工学研究科電子工学専攻後期 課程中退. 同年大阪大学工学部電子工学科助手, 1994 年同大学工学部電子制御機械工学科助教授, 現在に至る。この間 1986 年から 88 年米国マサ チューセッツ工科大学情報と決定システム研究所 客員研究員. 制御理論の研究に従事 (工学博士).

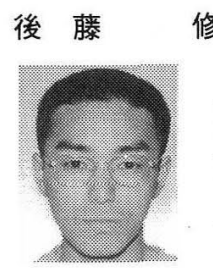

修（正会員）

1994 年大阪大学工学部電子制御機械工学科卒 業. 1996 年大阪大学大学院工学研究科電子制御 工学専攻前期課程卒業, 同年住友金属工業（株） に入社，現在に至る。鉄道用制御付台車の開発に 従事.

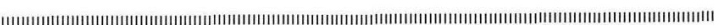

